\title{
Spatial-Temporal Patterns and Controls of Evapotranspiration across the Tibetan Plateau (2000-2012)
}

\author{
Hao Zhang, ${ }^{1,2}$ Jian Sun, ${ }^{2}$ and Junnan Xiong ${ }^{1}$ \\ ${ }^{1}$ School of Civil Engineering and Architecture, Southwest Petroleum University, Chengdu 610500, China \\ ${ }^{2}$ Synthesis Research Centre of Chinese Ecosystem Research Network, Key Laboratory of Ecosystem Network Observation and Modelling, \\ Institute of Geographic Sciences and Natural Resources Research, Chinese Academy of Sciences, Beijing 100101, China
}

Correspondence should be addressed to Jian Sun; sunjian@igsnrr.ac.cn and Junnan Xiong; neu_xjn@163.com

Received 22 January 2017; Revised 16 June 2017; Accepted 5 July 2017; Published 9 August 2017

Academic Editor: Cesar Azorin-Molina

Copyright (C) 2017 Hao Zhang et al. This is an open access article distributed under the Creative Commons Attribution License, which permits unrestricted use, distribution, and reproduction in any medium, provided the original work is properly cited.

Evapotranspiration (ET) is a key factor to further our understanding of climate change processes, especially on the Tibetan Plateau, which is sensitive to global change. Herein, the spatial patterns of ET are examined, and the effects of environmental factors on ET at different scales are explored from the years 2000 to 2012. The results indicated that a steady trend in ET was detected over the past decade. Meanwhile, the spatial distribution shows an increase of ET from the northwest to the southeast, and the rate of change in ET is lower in the middle part of the Tibetan Plateau. Besides, the positive effect of radiation on ET existed mainly in the southwest. Based on the environment gradient transects, the ET had positive correlations with temperature $(R>0.85, p<0.0001)$, precipitation $(R>0.89, p<0.0001)$, and NDVI $(R>0.75, p<0.0001)$, but a negative correlation between ET and radiation $(R=$ $0.76, p<0.0001)$ was observed. We also found that the relationships between environmental factors and ET differed in the different grassland ecosystems, which indicated that vegetation type is one factor that can affect ET. Generally, the results indicate that ET can serve as a valuable ecological indicator.

\section{Introduction}

With a variable global climate, evapotranspiration, which has not escaped our concern, is seen as the crux to comprehending soil-vegetation-atmosphere interactions [1]. The word evapotranspiration is composed of evaporation and transpiration. The former is the process by which water from the Earth's surface waters changes from liquid to vapour and goes into the atmosphere, and the latter refers to the process by which the water in plants passes through the stomata and spreads to the exterior [2]. Evaporation is a component not only of the surface heat balance but also of the hydrological cycle [3]; it has the functions of regulating temperature, increasing humidity, and affecting the ecological environment, and it thus affects the sustainable development of society and economy [4]. Approximately $60 \%$ to $65 \%$ of the Earth's precipitation reenters the atmosphere via evaporation [5, 6]. Moreover, a close relationship between evapotranspiration and meteorological variables (temperature, precipitation, radiation, and wind speed and humidity) has been reported [7-9]. Therefore, the variation in evapotranspiration is a vital indicator for the drivers of climate change [10, 11], and it can serve as a valuable tool in investigations of ecological environment change and the impacts that human activities have on it.

Many methods and significant comparative analyses for evaluating evapotranspiration have been carried out at the global scale for many years [12-17]. The most common way is to use remote sensing data to calculate the evapotranspiration by employing the surface energy balance with parameters such as meteorological data [18], which has been used in China, including in the northwest of Yunnan province [19]. Long-term estimation methods of evapotranspiration mainly involve water balance [20-22], combination, and complementary methods $[23,24]$, and measurement methods mainly involve sap flow, lysimeter, and eddy covariance methods, which underestimate the measurement [25]. Analyses of the spatial distribution of global ET have shown an overall increasing trend from high-altitude or high-latitude cold areas to low-latitude regions such as tropical rain forest, 
which show high year-round ET values with lower seasonal variability than the temperate or subarctic climes [26, 27]. Evapotranspiration has increased, which is attributed to increases in precipitation (in Poyang Lake watershed) [28], incident solar radiation (in China or tropical ecosystems) [29], wind speed, and sunshine duration (in arid region of China) [30]. The effect of temperature on evapotranspiration has also been discussed in Australia [31], India [32], Iran [33], and North China [34]. The evaporation paradox explains that pan evaporation has decreased despite the increase in annual temperature, but it does not exist in northeast and southwest China [11, 35].

The mean annual temperature in the Tibetan Plateau has had significant changes with a remarkable warming trend since the 1980s $[36,37]$. The temperature in the region has risen at an average of $0.05^{\circ} \mathrm{C}$ per year from 1981 to 2010 , and a warming trend of $0.02^{\circ} \mathrm{C}$ per year was observed in the 30 years before 2000 [38]. The daytime temperature is greater than $10^{\circ} \mathrm{C}$ in the growing season from June to September $[39,40]$. Glaciers melt, ice lakes increase, and glacial debris flows become active under global warming [41]. There are special climatic conditions and natural environments in the Tibetan Plateau that are sensitive to global change [42]. The Tibetan Plateau contains the headwaters of the Yangtze River, Yellow River, and other rivers, which are the main rivers of China; hence, the alpine ecosystem here has significant functions [43].

Consequently, the comprehensive study of changes of actual evapotranspiration (ET) and the relationships between ET and environmental factors is important for the Tibetan Plateau. Recently, a paper using a modified model to estimate ET with a more accurate temporal and spatial distribution has been published; the better quality is attributed to local validating parameters and different input driving variables [44]. The aim of this paper is to examine the spatial-temporal patterns of ET, with an emphasis on the relationships between ET and environmental factors such as temperature, precipitation, solar radiation, and NDVI at different scales. Further, the above issues are discussed in different ecosystems, such as alpine meadows, alpine steppes, desert steppes, and forests, across the Tibetan Plateau (with the exception of barren land in the north) from 2000 to 2012.

\section{Materials and Methods}

2.1. Study Area. Our study area, between $73^{\circ} 19^{\prime}-104^{\circ} 47^{\prime} \mathrm{E}$ and $26^{\circ} 00^{\prime}-39^{\circ} 47 \mathrm{~N}$, which covers an area of 2.5 million $\mathrm{km}^{2}$, is the highest plateau in the world, and it has been called the roof of the world and the third pole of the Earth $[45,46]$. The Tibetan Plateau, located in southwest China, features several climate types. It not only has the characteristics of the hot and rainy equatorial region and the north with a cold and dry climate but also has a number of microclimates and the plateau alpine zone with its obvious vertical distribution of climate $[47,48]$. The unique atmospheric conditions, topography (such as high elevation), and weather systems result in all sorts of chaos and strange plateau climate zones that are fragile and vulnerable to the effects of global climate change [42, 48]. Alpine steppes and alpine meadows cover most of the study area, with forests occurring mainly in the south and southeast of the plateau and large tracts of bare land such as desert steppes occurring in the northwest (Figure 1).

2.2. Data Compilation. The remote sensing data used in this paper are from the moderate resolution imaging spectroradiometer (MODIS) imagery provided by the United States National Aeronautics and Space Administration (NASA). The MOD16 global ET product provides vital information for water resource management by calculating the regional water and energy balance. The NDVI data are retrieved from atmosphere-corrected and bidirectional surface reflectance. From the two highest NDVI values for the demand of cloud-free images or better photographing quality images, it selects the closest-to-nadir pixel. All of the MODIS data can be downloaded for free at the NASA website (https://modis.gsfc.nasa.gov).

Temperature, precipitation, and radiation data were downloaded from the China Meteorological Administration; they were collected from 127 meteorological observatories around and within the research region from 2000 to 2012 (China Meteorological Data Sharing Service System, available online: http://data.cma.cn/). To acquire detailed temperature, precipitation, and radiation factors for each sampling site and pixel, we resampled the interpolated data in ArcGIS (v. 10.2), in which the meteorological data were interpolated at $5 \mathrm{~km} \times 5 \mathrm{~km}$ resolution via the kriging method.

2.3. Data Analysis. The mean annual temperature, precipitation, and radiation were calculated using meteorological data from 2000 to 2012 . We obtained precipitation values between 19.54 and $1676 \mathrm{~mm}$, temperature values between $-3.58^{\circ} \mathrm{C}$ and $15.86^{\circ} \mathrm{C}$, and radiation values between 4539 and $7235 \mathrm{MJ} \mathrm{m}^{-2}$ from the spatial distribution across the Tibetan Plateau. Using cross-validation, we compared the observed and predicted values (from meteorological station and kriging process, resp.) for temperature $\left(R^{2}=0.98\right)$, radiation $\left(R^{2}=0.73\right)$, and precipitation $\left(R^{2}=0.92\right)$ and found similar spatial distributions and approximate numerical ranges as those obtained in another report in the study area [49].

We obtained the annual and monthly ET distributions over the last 10 years using a raster calculator in ArcGIS. Because the quality of the MOD16 global ET product is not particularly high, we made a comparative analysis of our result with those from other studies. The spatial change rate of ET and the spatial correlation between ET and four environmental factors-temperature, precipitation, radiation, and NDVI-were also obtained with a raster calculator by using least squares [50].

$$
\begin{aligned}
\beta & =\frac{n \sum x y-\sum x \sum y}{n \sum x^{2}-(x)^{2}} \\
r & =\frac{n \sum_{i=1}^{n} x_{i} y_{i}-\sum_{i=1}^{n} x_{i} \sum_{i=1}^{n} y_{i}}{\sqrt{n \sum_{i=1}^{n} x_{i}^{2}-\left(\sum_{i=1}^{n} x_{i}\right)^{2}}-\sqrt{n \sum_{i=1}^{n} y_{i}^{2}-\left(\sum_{i=1}^{n} y_{i}\right)^{2}}} .
\end{aligned}
$$

Factor $n$ is the number of years during the study and $x$ and $y$ are the year and ET, respectively, in the first formula. 


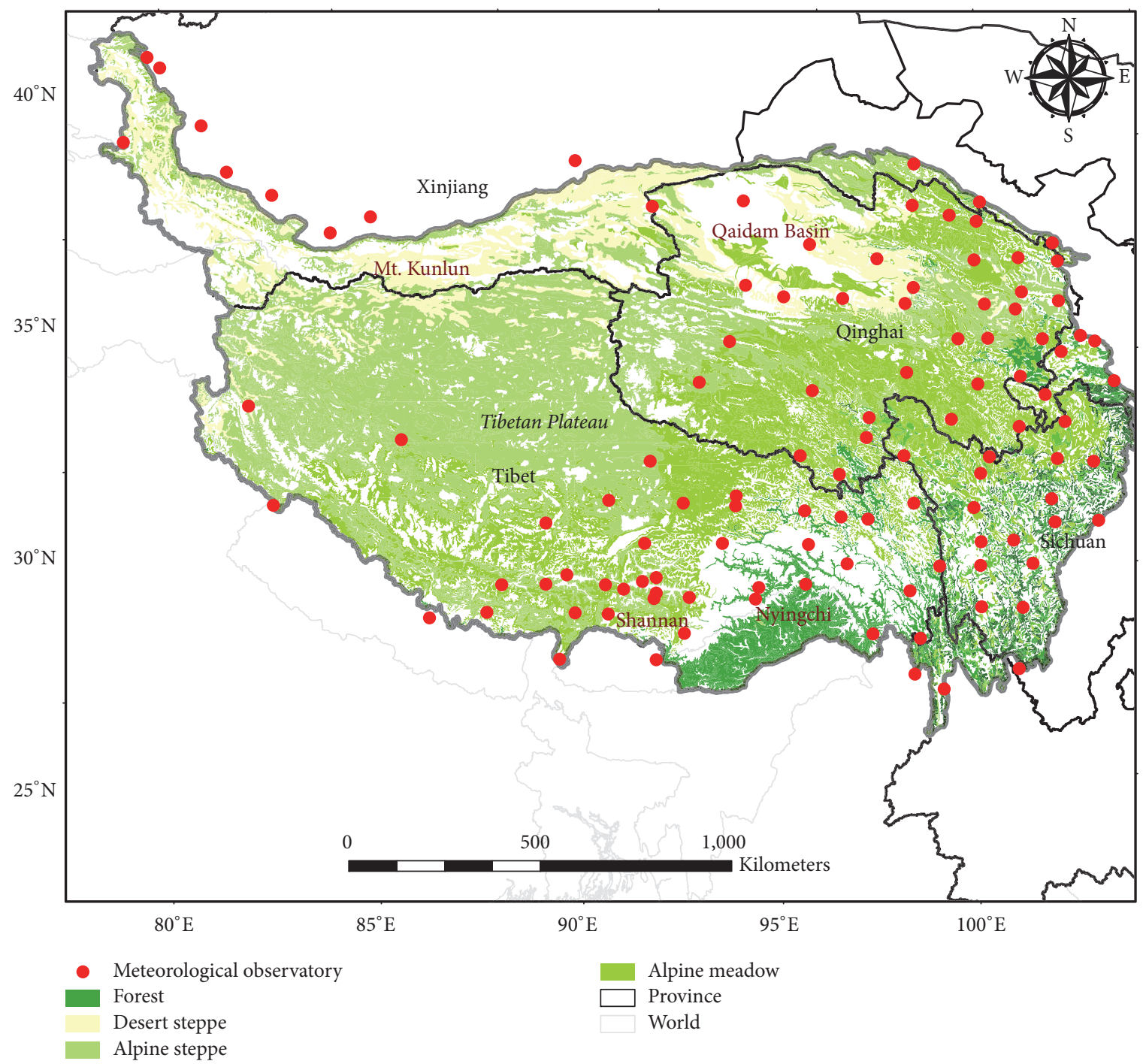

Figure 1: The study area across Tibetan Plateau. The ecosystems contained alpine meadow, alpine steppe, desert steppe, and forest.

In the latter, $n$ is the same, $x_{i}$ is the environmental factor (temperature, precipitation, radiation, and NDVI), and $y_{i}$ is the ET.

\section{Results}

3.1. Spatial-Temporal Patterns of ET across the Tibetan Plateau. The mean value of ET gradually increased to the maximum at approximately $60 \mathrm{~mm}$ in July and then decreased throughout the year (Figure 2(a)), and the minimum ET of approximately 30 occurred in January or December. The annual value had a stationary trend (the average rate of change was $-2.8 \mathrm{~mm} \mathrm{yr}^{-1}$ ), fluctuating between 450 and $500 \mathrm{~mm}$ from 2000 to 2012, except in 2006 and 2007, which had an obvious decline to the minimum value, $427 \mathrm{~mm}$ (Figure 2(b)).

The comparison of ET dynamics in different ecosystems indicated that the ET values in the forest had the least interannual variability (the average rate of change rate was $-0.45 \mathrm{~mm} \mathrm{yr}^{-1}$ ) and highly outperformed the others (Figure 2). The ET values showed a similar tendency to fluctuate in the different ecosystems, particularly in alpine meadow and all ecosystems. Moreover, ET in alpine steppe and desert steppe was the least susceptible to seasonal effects, which fluctuated between $20 \mathrm{~mm} \mathrm{mon}^{-1}$ and $30 \mathrm{~mm} \mathrm{mon}^{-1}$. Based on the value of ET, the fact was discovered expressly that the ecosystems could be divided into the following three groups, ordered from high to low ET values: forest (approximately $660 \mathrm{~mm} \mathrm{yr}^{-1}$ ), alpine meadow and all ecosystems (between $450 \mathrm{~mm} \mathrm{yr}^{-1}$ and $550 \mathrm{~mm} \mathrm{yr}^{-1}$ ), and alpine steppe and desert steppe (between $250 \mathrm{~mm} \mathrm{yr}^{-1}$ and $350 \mathrm{~mm} \mathrm{yr}^{-1}$ ).

The spatial distribution of ET over the Tibetan Plateau shows an increase from the northwest to the southeast in Figure 3(a). The highest ET regions were in the south of Shannan Prefecture and Nyingchi in Tibet, with ET values ranging from $888 \mathrm{~mm} \mathrm{yr}^{-1}$ to $1340 \mathrm{~mm} \mathrm{yr}^{-1}$. The lowest ET regions were in the western part of the Tibetan Plateau and 


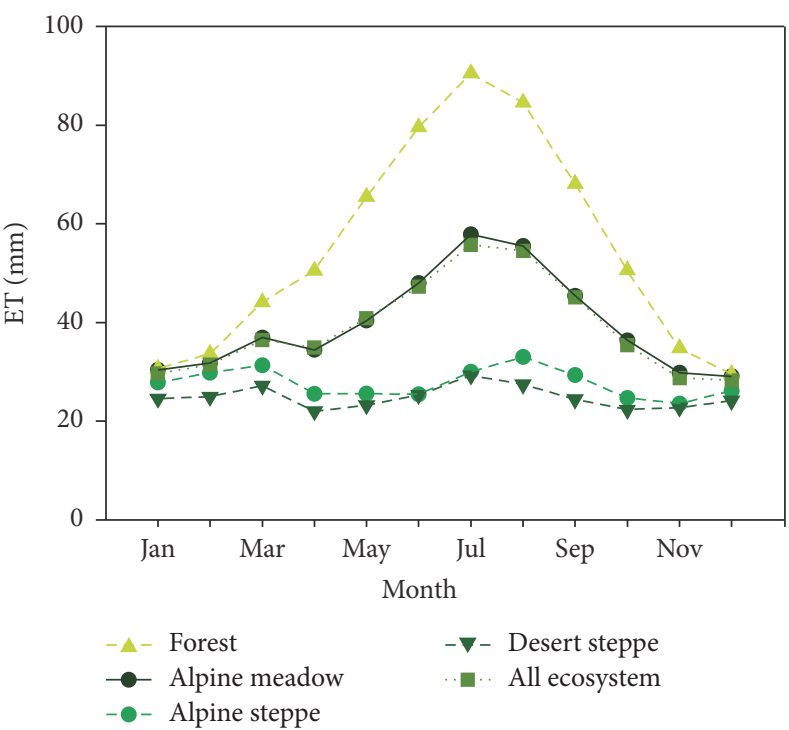

(a)

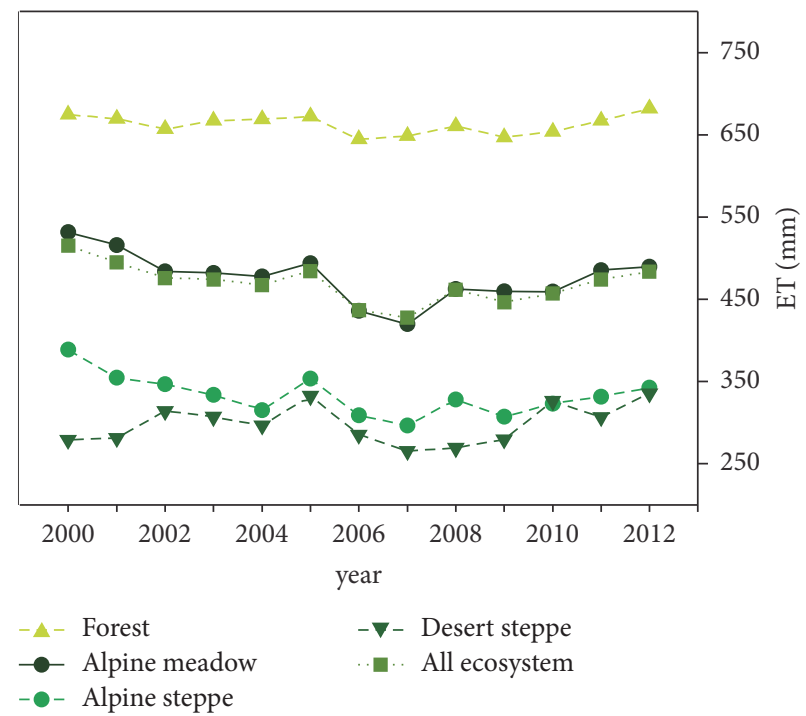

(b)

FIgURE 2: Temporal patterns of ET across the Tibetan Plateau. Graphs (a) and (b) represent variation ET of months January-December and years 2000-2012, respectively.

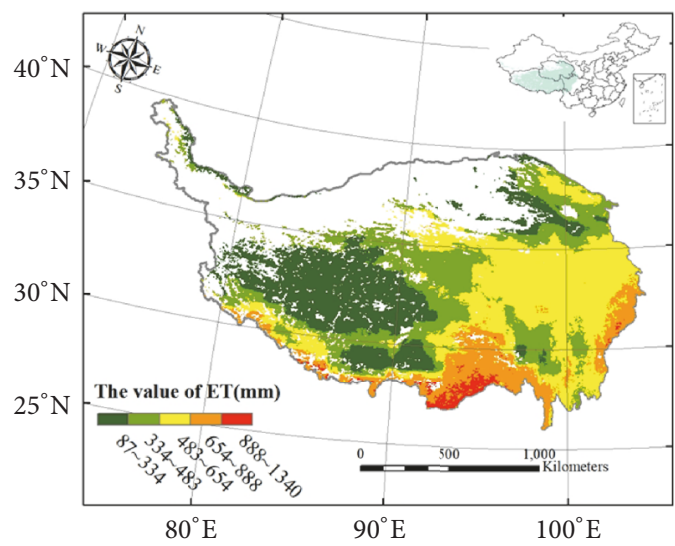

(a)

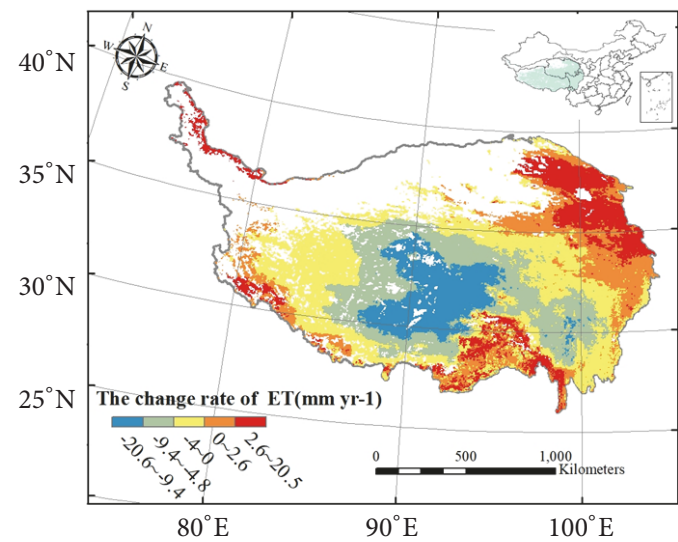

(b)

FIgURE 3: Spatial patterns and dynamics of ET across the Tibetan Plateau. Graphs (a) and (b) represent distribution and variation of ET, respectively.

northern Tibet, with ET values ranging from $87.4 \mathrm{~mm} \mathrm{yr}^{-1}$ to $334.2 \mathrm{~mm} \mathrm{yr}^{-1}$. The change rate of ET was positive in the edge areas, except north and southeast of the Tibetan Plateau, forming an almost ring-like distribution (Figure 3(b)). In addition, the most important negative change region emerged in the middle part of the Tibetan Plateau, which included almost all of Tibet and had a value lower than $-94 \mathrm{~mm}$ per 10 years.

The spatial pattern of ET and ecosystems was consistent in the Tibetan Plateau; where there was forest or desert steppe, there was a higher or lower ET, respectively, which is fairly similar to the change rate of ET. However, unlike the distribution of ET value, the change rate of ET in alpine steppe and alpine meadow was complex and had a widespread area that included all rate classifications.
3.2. Variations of ET with Environmental Factors across the Tibetan Plateau. The spatial correlation and significance between ET and four environmental factors (temperature, precipitation, radiation, and NDVI) were calculated and are shown in Figures 4 and 5. Compared with several other environmental factors, the area in which there was a positive correlation between precipitation and ET was the largest, followed by NDVI, radiation, and temperature. The strong positive correlation between ET and precipitation emerged mainly in the east and southwest parts of the Tibetan Plateau, where most of the area is dominated by the positive correlations (Figure 4(b)). The significant correlations were also distributed in this region (Figure 5(b)). There were no obvious spatial distribution characteristics in the positive correlations between ET and NDVI, although a few areas 


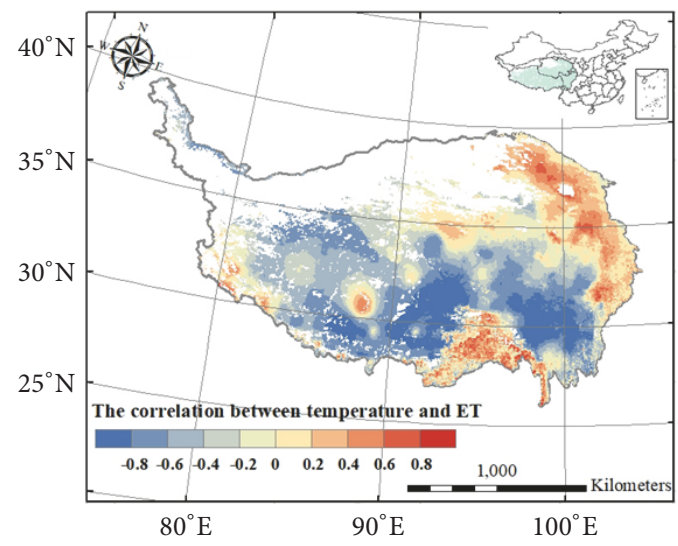

(a)

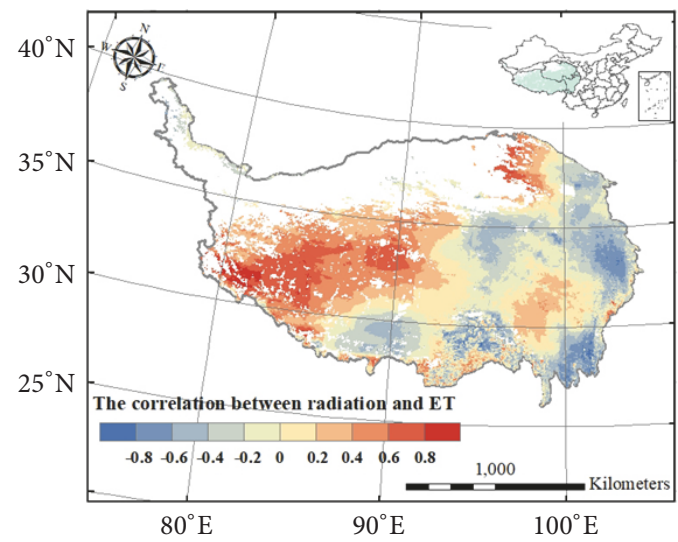

(c)

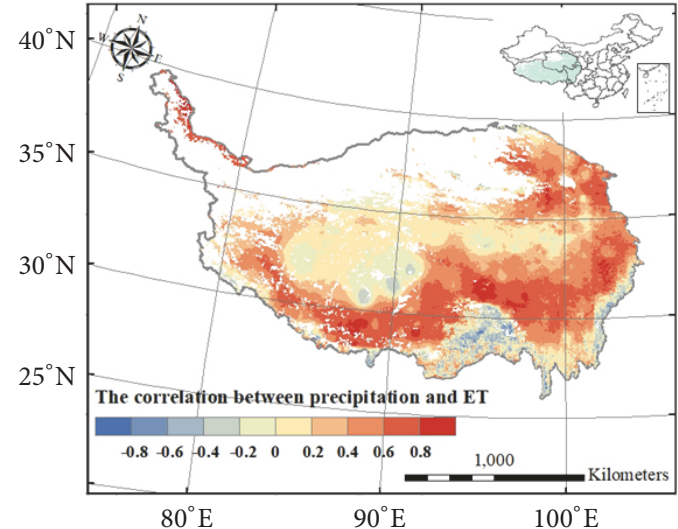

(b)

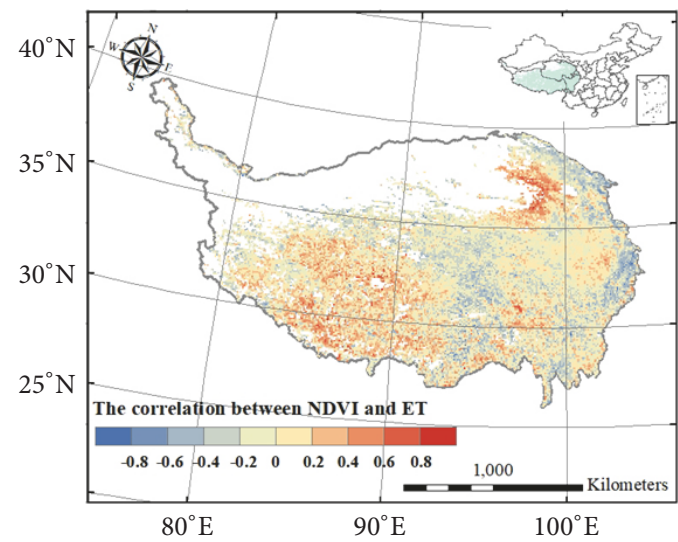

(d)

FIGURE 4: Responses of ET to variation of four environmental factors across the Tibetan Plateau. Graphs (a), (b), (c), and (d) represent the variation with temperature, precipitation, radiation, and NDVI, respectively.

of significant correlations were spread throughout the study area (Figures 4(d) and 5(d)). The areas of the positive correlations between ET and radiation were distributed in the southwest Tibetan Plateau, negative correlations were distributed in the east and south of the area (Figure 4(c)), and significant correlations were distributed in the west of Tibet and, secondarily, southeast of Tibetan Plateau (Figure 5(c)). The areas with significant correlations of ET with temperature were larger than those with precipitation, radiation, and NDVI, and the area that had a negative correlation was distributed in Tibet and western Sichuan (Figures 4(a) and 5(a)).

Figure 6 shows the proportion of significant to nonsignificant correlations in the grassland ecosystems. There were fewer regions with significant correlations. The percentage of significant changes of ET with temperature (negative significant) and precipitation (positive significant) was higher than those with radiation and NDVI. In these cases, with four environmental factors, only the correlation of ET with temperature in alpine steppes was approximately $40 \%$ (positive significant and negative significant together accounting for 36 percent).
3.3. Variations of ET with Typical Environmental Gradients. To examine the responses of ET to the changing environmental conditions, gradient transects of temperature, precipitation, radiation, and NDVI were constructed (Figure 7). There were two gradients (gradients $\mathrm{a}$ and $\mathrm{b}$ ) in each environmental condition, except the last one, which contained a random selection of sites of NDVI.

The ET had consistent linear correlations with temperature and precipitation in both gradients $\mathrm{a}$ and $\mathrm{b}$ (Figures $8(\mathrm{a})(\mathrm{A}), 8(\mathrm{a})(\mathrm{B}), 8(\mathrm{~b})(\mathrm{A})$, and $8(\mathrm{~b})(\mathrm{B}))$. There were positive linear correlations between temperature and ET with $R=$ $0.88, p<0.0001$, in gradient a and $R=0.85, p<0.0001$, in gradient $\mathrm{b}$ and between precipitation and ET in the two precipitation gradients $(R=0.89, p<0.0001$, and $R=$ $0.94, p<0.0001$, resp.). Nevertheless, the linear correlations between ET and radiation differed from temperature and precipitation; it had opposing linear relationships in the two radiation gradients $(R=0.95, p<0.0001 ; R=0.76, p<0.0001)$ (Figures $8(\mathrm{c})(\mathrm{A})$ and $8(\mathrm{c})(\mathrm{B})$ ). In addition, a positive linear correlation existed between NDVI and ET $(R=0.75, p<$ 0.0001 ) in the randomly selected sites of NDVI (Figure 9). 


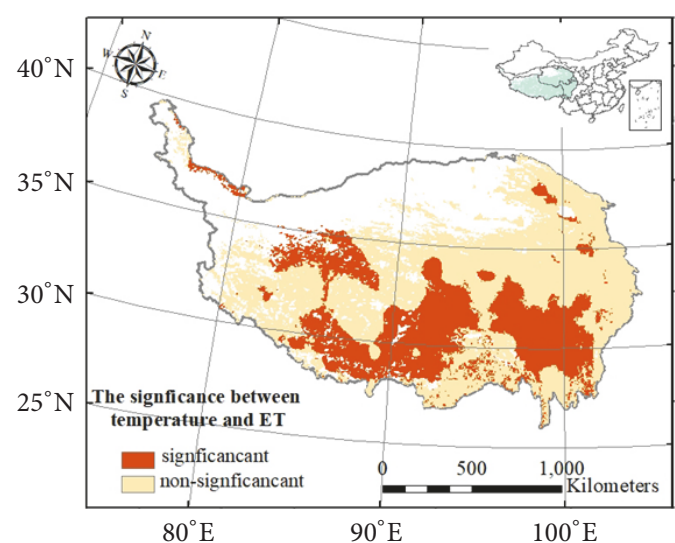

(a)

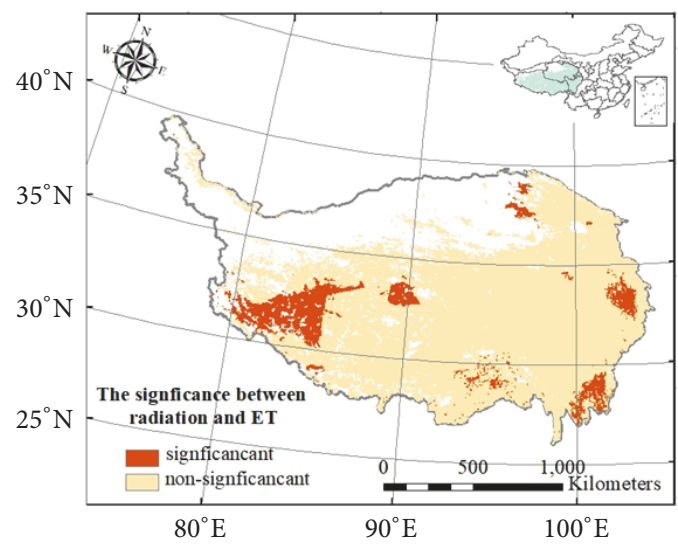

(c)

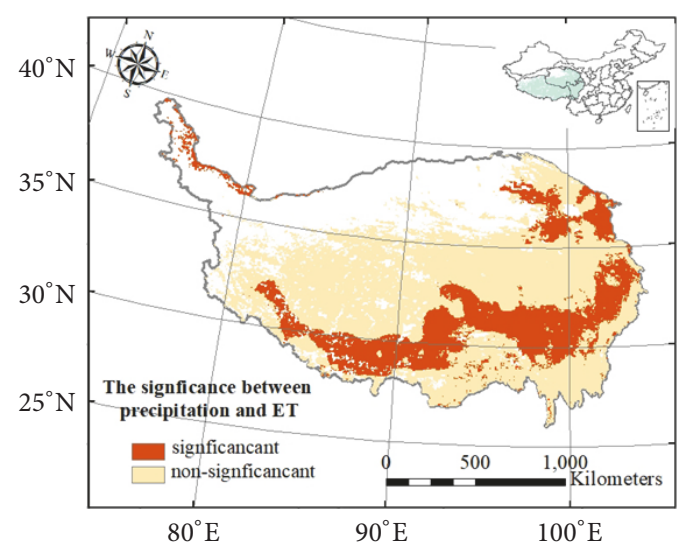

(b)

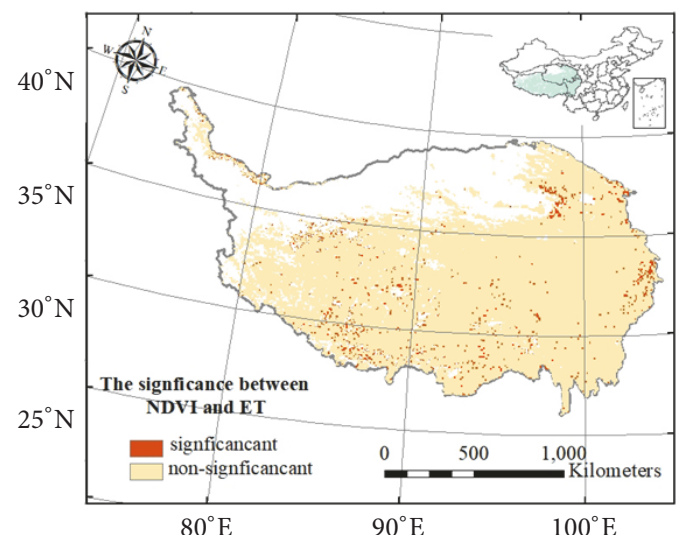

(d)

FIGURE 5: The significant changes of ET with four environmental factors across the Tibetan Plateau. Graphs (a), (b), (c), and (d) represent the variations with temperature, precipitation, radiation, and NDVI, respectively.

\section{Discussion}

4.1. Dynamics of ET. The spatial distribution of ET over Tibetan Plateau in our study shows a decrease from the southeast to the northwest. These results are consistent with those obtained using the Lund-Potsdam-Jena Dynamic Global Vegetation Model [43]. Much previous research has demonstrated a positive correlation between temperature and ET in study areas such as the Guanzhong region of Shanxi [51], northeast China [52], and the Songhua River basin [53]. However, the most important factor in the change of ET is precipitation [43] in the Tibetan Plateau and northwest Yunnan [19], which is in agreement with our study both in temporal distribution and in spatial distribution (Figures 2 and $4(\mathrm{~b}))$. The ET value is highest in the summer, when the precipitation is also largest [54]. Moreover, our study discovered that the value was nearly constant, fluctuating between 450 and $500 \mathrm{~mm}$ from 2000 to 2012, with the exception of the obvious decline in 2006. Similarly, the precipitation was reduced in 2006 [55]. The growth trend of ET in the spatial distribution from northwest to southeast is almost similar to that of precipitation. Comparisons of ET in different ecosystems indicated that the ET value in the forest was much higher than that in other areas. Forests occur mainly in western Sichuan, the southern mountain regions of Tibet, and deep ravine areas, that is, in regions where the larger values of ET are distributed [37]. After forest, the values in alpine meadow are higher than those in alpine steppe, which in turn are higher than those in desert steppe, which mainly occurs in the Qaidam Basin and on Mt. Kunlun.

As the climate changes, we are seeing a decline of ET in many parts of the world, except in China and southern India [16]. The change of ET was positive in the edge area, except at the northern and southeastern edge of the Tibetan Plateau. ET increased in this region, partly due to the increase in precipitation [50, 56-58]. However, ET decreased in the middle part of the Tibetan Plateau, including almost all of Tibet. Alpine meadow occurs almost entirely here as well. The temperatures in the area are lower than those in other grassland ecosystems because of the high altitude, which is probably one of the factors that limit ET. The distribution (Figure 4(a)) of spatial correlation between ET and temperatures indicates that increase in temperatures was correlated to decrease in ET, but the sunshine duration, humidity, and wind speed all showed decreasing trends from 1981 to 2010 which was one of the reasons [43]. The cause of 


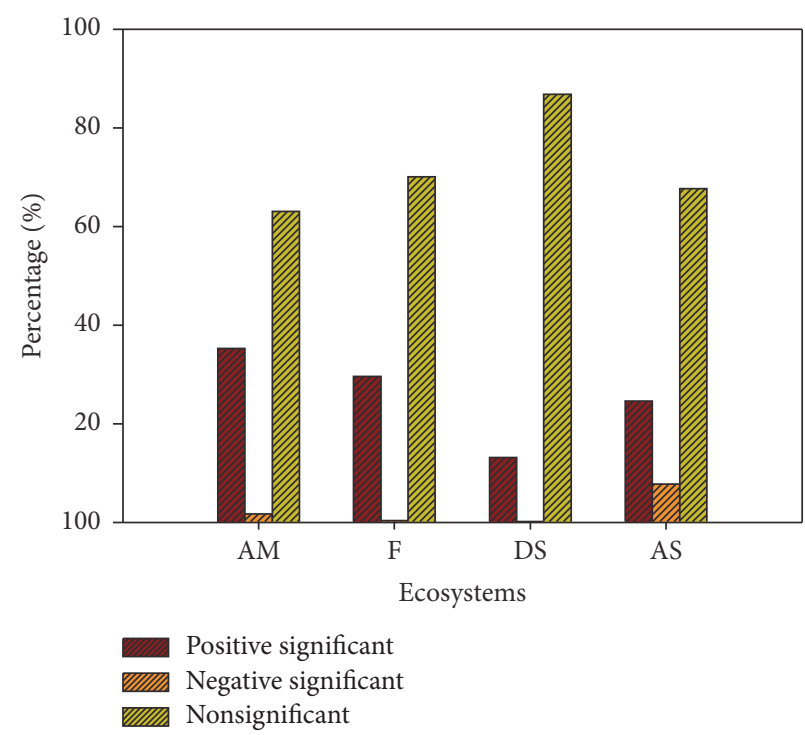

(a)

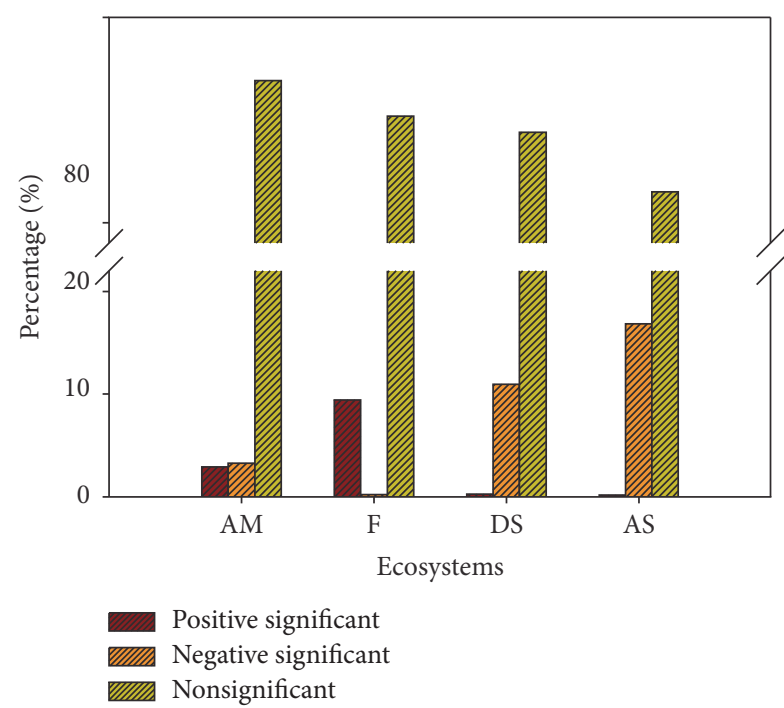

(c)

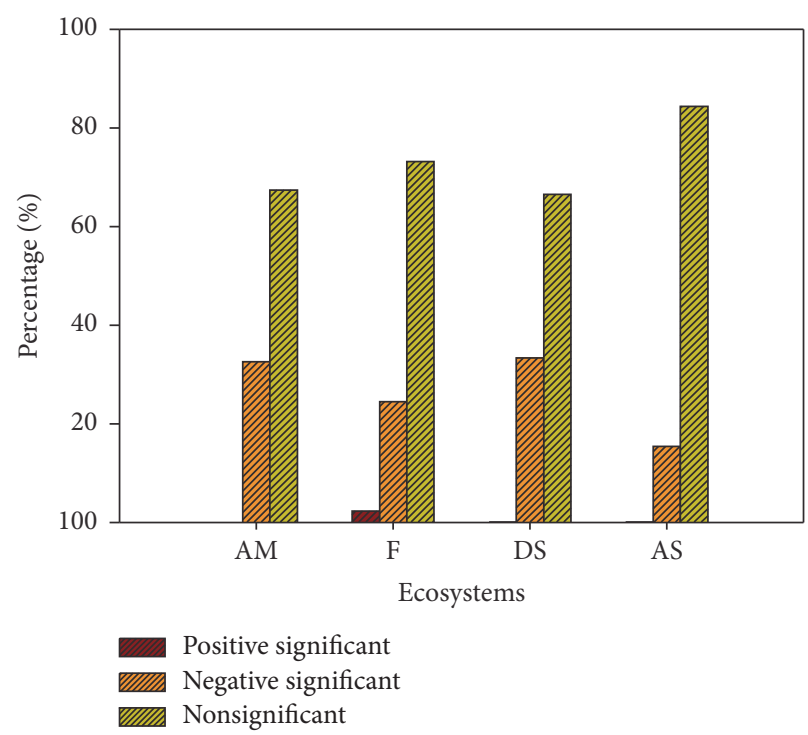

(b)

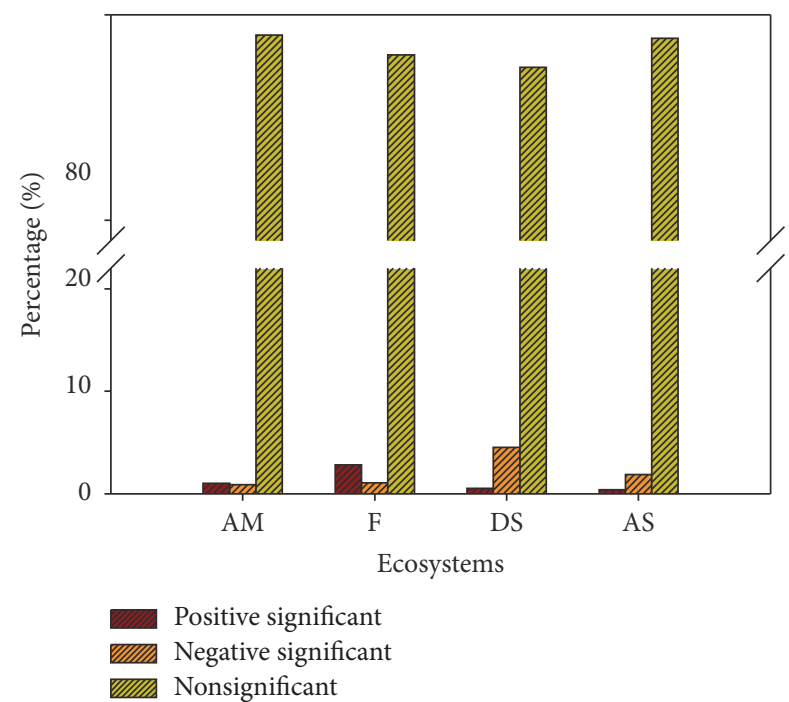

(d)

FIGURE 6: The percentage of significant changes of ET with four environmental factors across the Tibetan Plateau. Graphs (a), (b), (c), and (d) represent the variation with temperature, precipitation, radiation, and NDVI, respectively. Furthermore, alpine meadow, forest, desert steppe, and alpine steppe are represented by AM, F, DS, and AS, respectively.

the reduction in ET also may be human activities, which have been found to alter surface water conditions [59]. In addition, some transformations of alpine grassland in northern Tibet are borne from anthropogenic factors such as migratory grazing activities, roads, and residential distribution [60].

4.2. The Effect of Climate Factors on ET. In general, as the climate varies, ET is likely to be impacted; it is particularly hypersensitive to short-period meteorological conditions [61-64]. Three climate factors were researched in our paper.

The effect of precipitation on ET has been described previously [28]. Precipitation was compared with several other environmental factors; the area of positive correlation was largest across the Tibetan Plateau, where most of the area was dominated by the correlations. Studies also have found that there are an increase in precipitation over the $85 \%$ region, where ET increased simultaneously, and a decrease over the 70\% region, where ET reduced in the Tibetan Plateau [43]. The reason why higher precipitation may yield greater ET is that more precipitation could augment the water available for ET $[17,65]$.

ET is correlated with temperature, whether on the Great Plains [15], the Gulf Coast [14], or the Tibetan Plateau [66]. A positive linear correlation of ET and temperature existed in gradients a and b (Figures $8(\mathrm{a})(\mathrm{A})$ and $8(\mathrm{a})(\mathrm{B})$ ), and the increasing trend in ET exhibited complementary behaviour to reference evapotranspiration due to an increase in the air temperature [67]. The only area of negative correlation in 


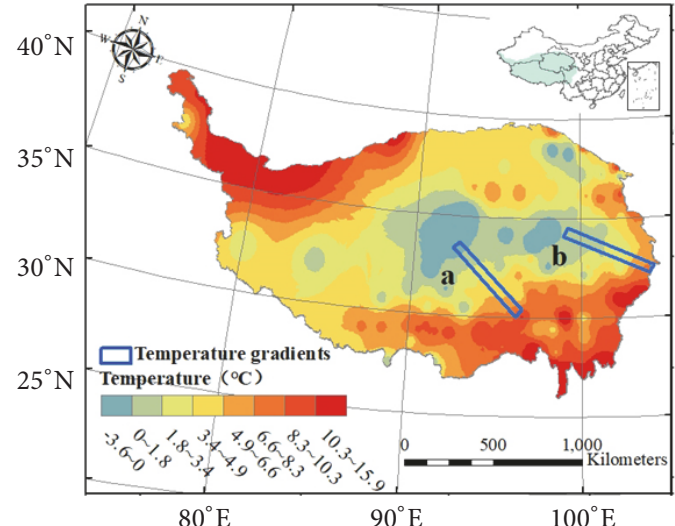

(a)

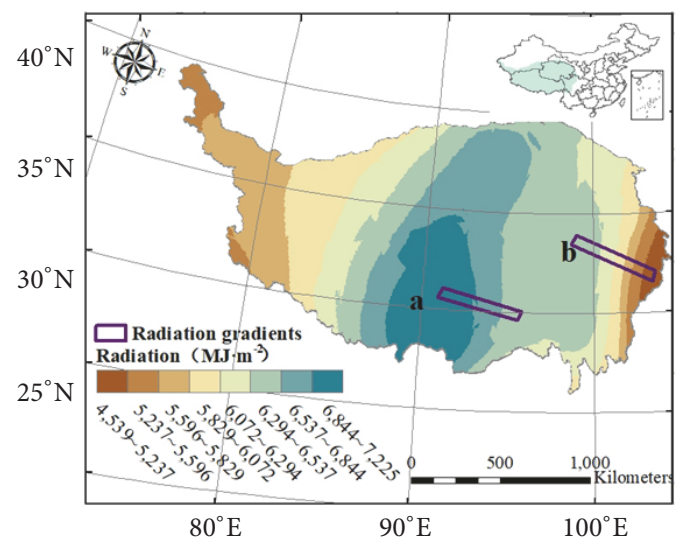

(c)

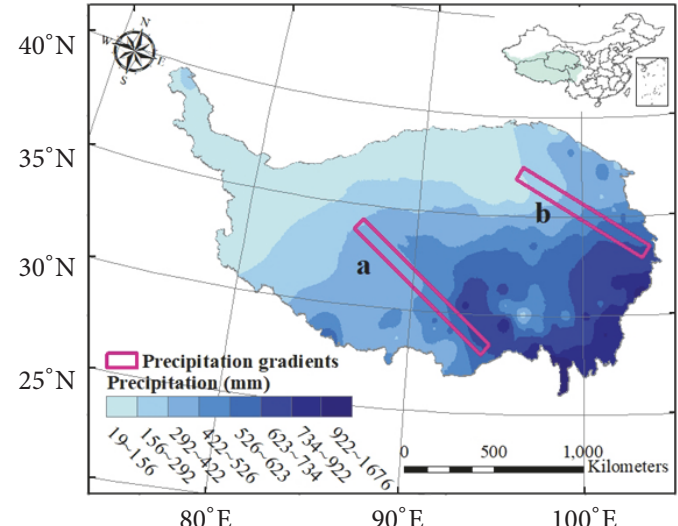

(b)

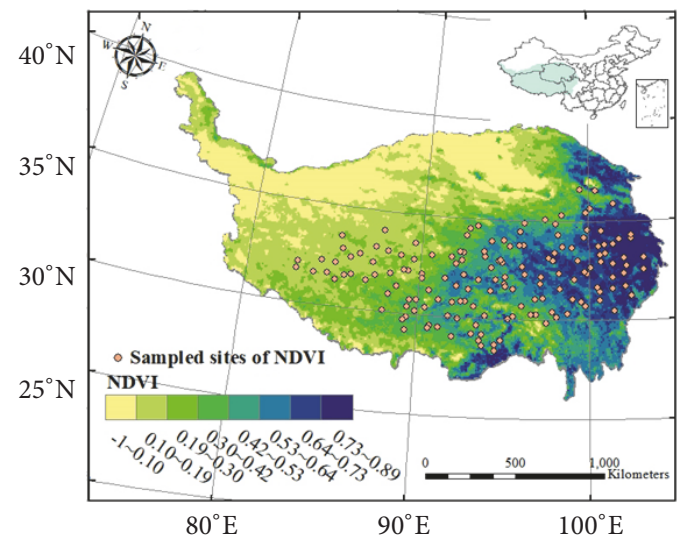

(d)

Figure 7: The typical environment gradients of four environmental factors across the Tibetan Plateau. Graphs (a), (b), (c), and (d) represent the gradients of temperature, precipitation, radiation, and NDVI, respectively.

the study area was distributed in Tibet and western Sichuan (Figure 4(a)), where alpine meadow is distributed. The reduction in ET was the result of decreasing the atmospheric water demand, and soil available water is the main factor limiting ET during the growing season in arid and semiarid lands [68]. With the temperature rising constantly, the Tibetan Plateau may suffer a shrinkage in water resources over the coming decades $[69,70]$. Temperature may not appear to have a significant impact on evapotranspiration when the temperature is sufficiently low [33]. The temperature in the area is less than that in other grassland ecosystems because of the high altitude; this is one of the factors that limit evapotranspiration [32]. With the temperature rising, the expected acceleration of the water circulation caused by an increase in ET and precipitation may not be consistent with the decrease in ET, according to multiple studies [44, 71]. As the climate becomes warmer and drier, water supply will be the main driving factor. Multiple factors can lead to a negative correlation, for example, the decrease in relative humidity or the significant decrease in wind speed and net solar radiation despite the rise in annual temperature. A negative correlation of temperature and ET was also found in the Haihe River Basin [59].
Furthermore, the area with positive correlations between ET and net solar radiation was distributed in the southwest Tibetan Plateau (Figure 4(c)). In these areas, the hydrological cycle and surface climate may be profoundly affected by radiation variation, which is the main energy source on the surface of the Earth $[9,29]$. Although negative correlations were distributed in the east and south of the area, linear relationships with opposite signs emerged in the two radiation gradients selected in our study (Figures 8(c)(A) and 8(c)(B)). One possible cause of a low ET is the small amount of energy used in ET, even in high radiation conditions, particularly in alpine meadow [25].

4.3. The Effect of Vegetation Characteristics on ET. The largest values of ET were observed in forest, followed by alpine meadow, alpine steppe, and, finally, desert steppe. Therefore, it is not surprising that the decreased ET from northwest to southeast was coincident with the direction of the ecosystem transitions. Many studies have confirmed this phenomenon and demonstrated the significant impact and correlation between ET and vegetation types, finding that climate factors contributed much of the variability in the observed ET [14, 72]. A positive linear correlation existed between NDVI and 


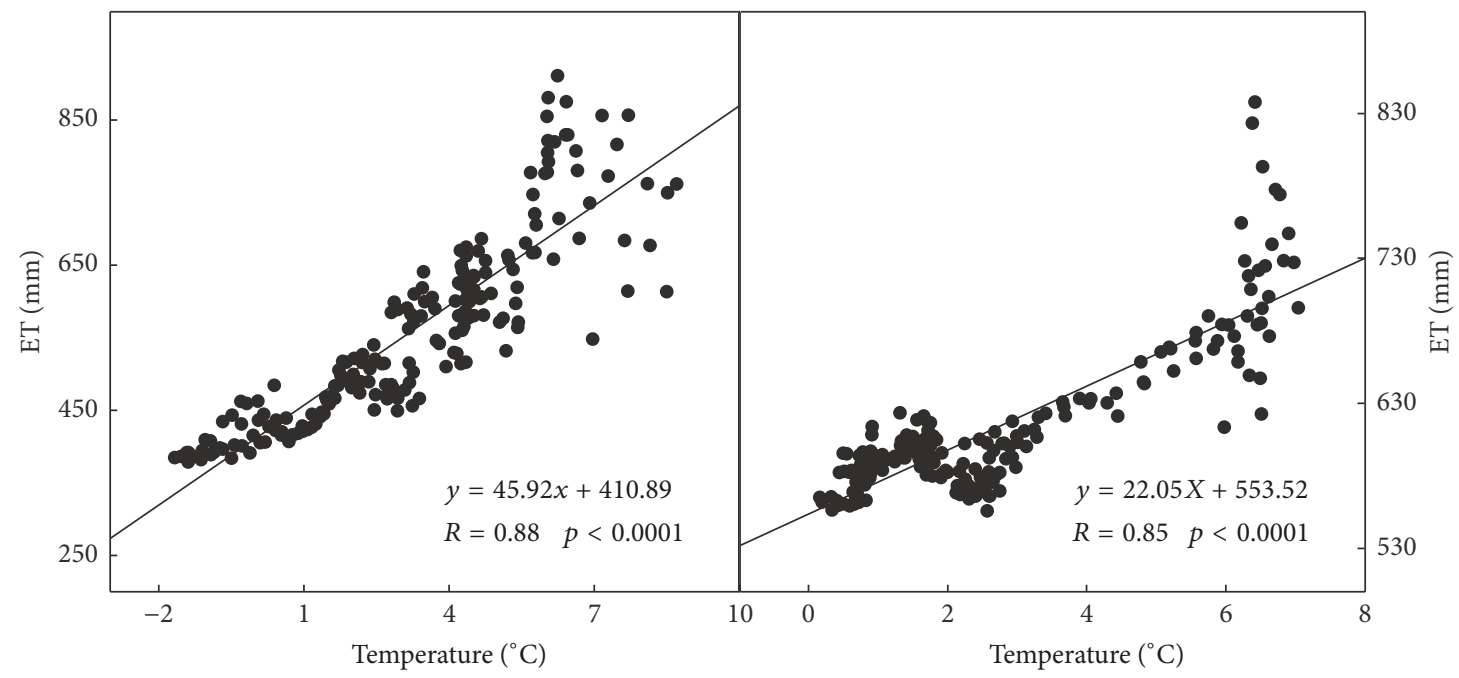

(A)

(B)

(a)

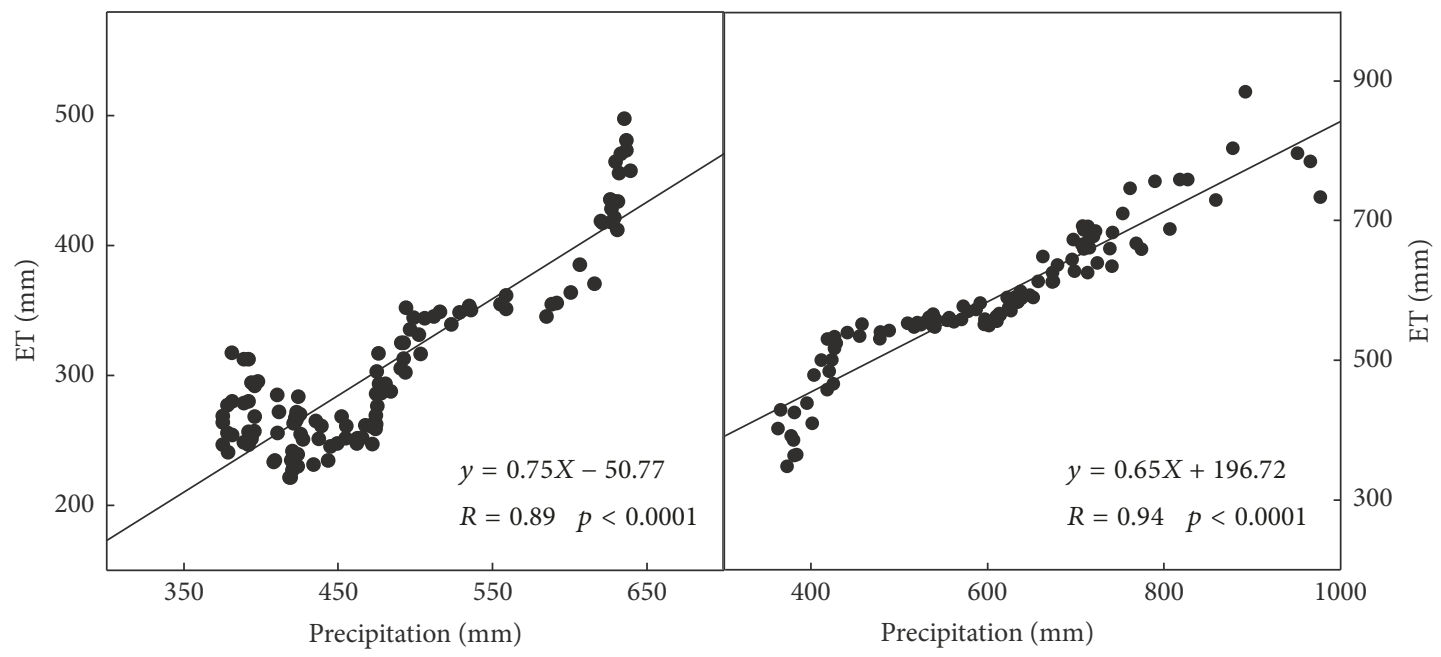

(A)

(B)

(b)

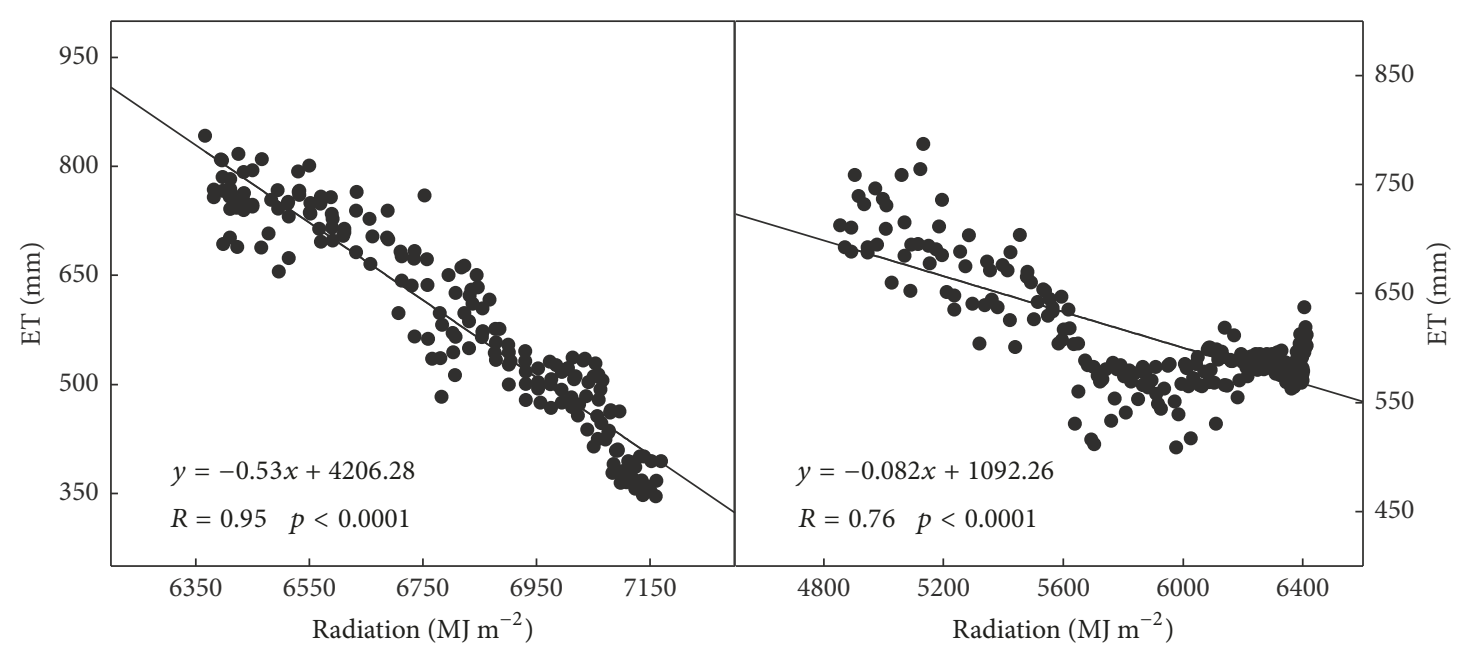

(A)

(B)

(c)

FIGURE 8: Relationship of three environmental factors with ET. Graphs (a)(A) and (a)(B) represent the relationship between ET with temperature in temperature gradients $a$ and $b$; graphs $(b)(A)$ and $(b)(B)$ with precipitation in precipitation gradients a and b; and graphs $(\mathrm{c})(\mathrm{A})$ and $(\mathrm{c})(\mathrm{B})$ with radiation in radiation gradients a and $\mathrm{b}$, respectively. 


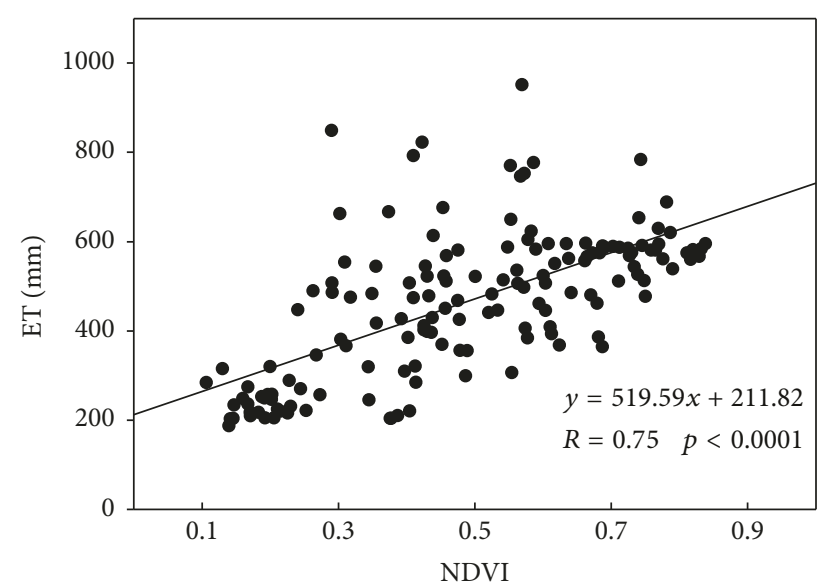

Figure 9: Relationship of NDVI with ET.

ET $(R=0.75, p<0.0001)$ in the randomly selected sites of NDVI (Figure 9).

The aforementioned negative correlation between ET and radiation mostly occurred in alpine meadow. We noted a lower efficiency in the annual radiation budget of alpine meadow compared with the lowland grasslands, which can receive even higher incident radiation $[73,74]$. The lower efficiency observed on this plateau is attributed to the much higher net longwave radiation compared with lowland grasslands or the global surface [75]. The subtle connection between biomass and ET is authenticated: the more biomass there is, the more precipitation is used efficiently [76]. In addition, the peak biomass in this alpine meadow lagged approximately 30 days behind the maximum ET [25].

Among all ecosystems, the ET value in a forest is the largest and steadiest. The reason why this kind of situation will appear in a forest is that forests can maintain a good amount of ET, even under a dry weather regime [77]. This may be due to the transpiration of trees, which can maintain ET by using deep roots to absorb underground water, and the grass forces transpiration to rely primarily on the occurrence of precipitation or the presence of top soil water [78]. This explains the small area of negative correlation relationship between ET and precipitation distributed in the southeast Tibetan Plateau, which is covered by forest (Figure 4(b)).

\section{Conclusions}

Using data from MODIS and meteorological stations in the Tibetan Plateau from 2000 to 2012, spatial-temporal patterns of ET were analysed with least squares regression. In addition, the effects of environmental factors on ET across transect scales and regional scales were explored. A steady trend in ET was detected over the past decade, and the largest value of ET occurred in June of each year. The growth trend of ET in the spatial distribution from northwest to southeast was similar to that of precipitation. The rate of ET increase was higher in the edge area, except at the northern and southeastern edge of the Tibetan Plateau, which was affected by low temperature. In addition, positive linear relationships existed between ET and meteorological variables (temperature, NDVI, and precipitation), with the most obvious effect on ET coming from precipitation. However, the opposite relationship emerged in the two radiation gradients. This apparent disaccord between different grassland ecosystems indicated that vegetation also has a strong influence on ET.

\section{Conflicts of Interest}

The authors declare that they have no conflicts of interest.

\section{Acknowledgments}

This research was funded by the National Science Foundation of China (Grant no. 41501057) and West Light Foundation of The Chinese Academy of Sciences.

\section{References}

[1] R. Nemani, M. White, P. Thornton et al., "Recent trends in hydrologic balance have enhanced the terrestrial carbon sink in the United States," Geophysical Research Letters, vol. 10, pp. 106-1-106-4, 2002.

[2] L. Song, Y. Yin, and W. U. Shaohong, "Advancements of the Metrics of Evapotranspiration, Progress in Geography," Advancements of the Metrics of Evapotranspiration, Progress in Geography, vol. 9, pp. 1186-1195, 2012.

[3] J. Li, S. Wang, Y. Li, K. Shang, and X. Dong, "The Evaporation Variation and Its Influence Factors in Xi'ning of Qinghai Province," Journal of Arid Meteorology, 2013.

[4] Z. Liu, K. G. Hubbard, X. Lin, and X. Yang, "Negative effects of climate warming on maize yield are reversed by the changing of sowing date and cultivar selection in Northeast China," Global Change Biology, vol. 19, no. 11, pp. 3481-3492, 2013.

[5] T. Oki and S. Kanae, "Global hydrological cycles and world water resources," Science, vol. 313, no. 5790, pp. 1068-1072, 2006.

[6] W. Brutsaert, Hydrology, Cambridge University Press, Cambridge, UK, 2005.

[7] N. Shan, Z. Shi, X. Yang, J. Gao, and D. Cai, "Spatiotemporal trends of reference evapotranspiration and its driving factors in the Beijing-Tianjin Sand Source Control Project Region, China," Agricultural and Forest Meteorology, vol. 200, pp. 322333, 2015.

[8] B. Temesgen, S. Eching, B. Davidoff, and K. Frame, "Comparison of some reference evapotranspiration equations for California," Journal of Irrigation and Drainage Engineering, vol. 131, no. 1, pp. 73-84, 2005.

[9] J. L. Monteith, "Solar radiation and productivity in tropical ecosystems," The Journal of Applied Ecology, vol. 9, no. 3, pp. 747766, 1972.

[10] N. Chattopadhyay and M. Hulme, "Evaporation and potential evapotranspiration in India under conditions of recent and future climate change," Agricultural and Forest Meteorology, vol. 87, no. 1, pp. 55-73, 1997.

[11] M. L. Roderick and G. D. Farquhar, "The cause of decreased pan evaporation over the past 50 years," Science, vol. 298, no. 5597, pp. 1410-1411, 2002.

[12] C.-Y. Xu and D. Chen, "Comparison of seven models for estimation of evapotranspiration and groundwater recharge 
using lysimeter measurement data in Germany," Hydrological Processes, vol. 19, no. 18, pp. 3717-3734, 2005.

[13] H. Alemu, G. B. Senay, A. T. Kaptue, and V. Kovalskyy, "Evapotranspiration variability and its association with vegetation dynamics in the Nile Basin, 2002-2011," Remote Sensing, vol. 6, no. 7, pp. 5885-5908, 2014.

[14] W. Sanford and D. L. Selnick, "Estimation of evapotranspiration across the conterminous united states using a regression with climate and land-cover data," Journal of the American Water Resources Association, vol. 49, no. 1, pp. 217-230, 2013.

[15] J. Sun, G. D. Salvucci, and D. Entekhabi, "Estimates of evapotranspiration from MODIS and AMSR-E land surface temperature and moisture over the Southern Great Plains," Remote Sensing of Environment, vol. 127, pp. 44-59, 2012.

[16] M. Jung, M. Reichstein, P. Ciais et al., "Recent decline in the global land evapotranspiration trend due to limited moisture supply," Nature, vol. 467, no. 7318, pp. 951-954, 2010.

[17] Y. Liu, Q. Zhuang, M. Chen et al., "Response of evapotranspiration and water availability to changing climate and land cover on the Mongolian Plateau during the 21st century," Global and Planetary Change, vol. 108, pp. 85-99, 2013.

[18] Z. Li, R. Tang, Z. Wan et al., "A review of current methodologies for regional evapotranspiration estimation from remotely sensed data," Sensors, vol. 9, no. 5, pp. 3801-3853, 2009.

[19] H. Yang, P. Luo, J. Wang et al., "Ecosystem evapotranspiration as a response to climate and vegetation coverage changes in Northwest Yunnan, China," PLoS ONE, vol. 10, no. 8, Article ID e0134795, 2015.

[20] B.-L. Xue, L. Wang, X. Li, K. Yang, D. Chen, and L. Sun, "Evaluation of evapotranspiration estimates for two river basins on the Tibetan Plateau by a water balance method," Journal of Hydrology, vol. 492, pp. 290-297, 2013.

[21] M. Rodell, J. S. Famiglietti, J. Chen et al., "Basin scale estimates of evapotranspiration using GRACE and other observations," Geophysical Research Letters, vol. 31, no. 20, 2004.

[22] G. M. Hornberger, Elements of physical hydrology, Johns Hopkins University Press, 1998.

[23] K. C. Wang and R. E. Dickinson, "A review of global terrestrial evapotranspiration: observation, modeling, climatology, and climatic variability," Reviews of Geophysics, vol. 50, no. 2, 2012.

[24] R. G. Allen, L. S. Pereira, T. A. Howell, and M. E. Jensen, "Evapotranspiration information reporting: I. Factors governing measurement accuracy," Agricultural Water Management, vol. 98, no. 6, pp. 899-920, 2011.

[25] J. Li, S. Jiang, B. Wang et al., "Evapotranspiration and its energy exchange in alpine meadow ecosystem on the Qinghai-Tibetan Plateau," Journal of Integrative Agriculture, vol. 12, no. 8, pp. 1396-1401, 2013.

[26] K. Zhang, J. S. Kimball, R. R. Nemani, and S. W. Running, "A continuous satellite-derived global record of land surface evapotranspiration from 1983 to 2006," Water Resources Research, vol. 46, no. 9, Article ID W09522, 2010.

[27] Q. Mu, F. A. Heinsch, M. Zhao, and S. W. Running, "Development of a global evapotranspiration algorithm based on MODIS and global meteorology data," Remote Sensing of Environment, vol. 111, no. 4, pp. 519-536, 2007.

[28] J. Liu, Q. Zhang, X. U. Chong-Yu, J. Q. Zhai, and X. L. Jin, "Change of actual evapotranspiration of poyang lake watershed and associated influencing factors in the past 50 years," Resources Environment in the Yangtze Basin, vol. 3, pp. 197-203, 2010.
[29] H. lin, X. Dong, X. Min, G. Rui, and Y. Hua, "Spatio-temporal variation of photosynthetically active radiation in China in recent 50 years," Journal of Geographical Sciences, vol. 6, pp. 803817,2010

[30] Y. Shen, C. Liu, M. Liu, Y. Zeng, and C. Tian, "Change in pan evaporation over the past 50 years in the arid region of China," Hydrological Processes, vol. 24, no. 2, pp. 225-231, 2010.

[31] M. L. Roderick and G. D. Farquhar, "Changes in Australian pan evaporation from 1970 to 2002," International Journal of Climatology, vol. 24, no. 9, pp. 1077-1090, 2004.

[32] A. Bandyopadhyay, A. Bhadra, N. S. Raghuwanshi, and R. Singh, "Temporal trends in estimates of reference evapotranspiration over India," Journal of Hydrologic Engineering, vol. 14, no. 5, pp. 508-515, 2009.

[33] H. Tabari, A. Aeini, P. H. Talaee, and B. S. Some'e, "Spatial distribution and temporal variation of reference evapotranspiration in arid and semi-arid regions of Iran," Hydrological Processes, vol. 26, no. 4, pp. 500-512, 2012.

[34] J. Feng, D. Yan, C. Li, F. Yu, and C. Zhang, "Assessing the impact of climatic factors on potential evapotranspiration in droughts in North China," Quaternary International, vol. 336, pp. 6-12, 2014.

[35] Z. T. Cong, D. W. Yang, and G. H. Ni, "Does evaporation paradox exist in China?" Hydrology Earth System Sciences Discussions, vol. 4, pp. 357-366, 2009.

[36] S. Wang and T. Yao, "Construction of mean annual temperature series for the last one hundred years in China," Quarterly Journal of Applied Meteorlolgy, 1998.

[37] Y. Yin, S. Wu, D. Zhao, D. Zheng, and T. Pan, "Modeled effects of climate change on actual evapotranspiration in different eco-geographical regions in the Tibetan Plateau, Journal of Geographical Sciences, vol. 23, no. 2, pp. 195-207, 2013.

[38] S. Wu, Y. Yin, D. Zheng, and Q. Yang, "Climatic trends over the Tibetan Plateau during 1971-2000," Journal of Geographical Sciences, vol. 17, no. 2, pp. 141-151, 2007.

[39] G. Miehe, S. Miehe, K. Bach et al., "Plant communities of central Tibetan pastures in the Alpine Steppe/Kobresia pygmaea ecotone," Journal of Arid Environments, vol. 75, no. 8, pp. 711-723, 2011.

[40] G. Miehe, K. Bach, S. Miehe et al., "Alpine steppe plant communities of the Tibetan highlands," Applied Vegetation Science, vol. 14, no. 4, pp. 547-560, 2011.

[41] P. Cui, R. Chen, L. Xiang, and F. Su, "Risk analysis of mountain hazards in Tibetan plateau under global warming," Progressus Inquisitiones De Mutatione Climatis, vol. 2, pp. 103-109, 2014.

[42] Z. Du and T. D. Yao, "Uplifting of Tibetan Plateau with Its Environmental Effects," Advances in Earth Science, vol. 5, pp. 451-458, 2006.

[43] Y. Yin, S. Wu, D. Zhao, D. Zheng, and T. Pan, "Impact of climate change on actual evapotranspiration on the Tibetan Plateau during 1981-2010," Dili Xuebao/Acta Geographica Sinica, vol. 67, no. 11, pp. 1471-1481, 2012.

[44] L. Song, Q. Zhuang, Y. Yin, X. Zhu, and S. Wu, "Spatio-temporal dynamics of evapotranspiration on the Tibetan Plateau from 2000 to 2010," Environmental Research Letters, vol. 12, no. 1, p. 014011, 2017.

[45] J. Sun, X. Qin, and J. Yang, "The response of vegetation dynamics of the different alpine grassland types to temperature and precipitation on the Tibetan Plateau," Environmental Monitoring and Assessment, vol. 188, no. 1, article 20, 2016. 
[46] M. D. Vivarelli and M. D. Vivarelli, "Ice core study-the past, the present and the future," Chinese Science Bulletin, vol. 13, pp. 1057-1064, 1997.

[47] F. U. Yang, "Countermeasures for Qinghai-Tibet Plateau to Cope with Climate Change and Ecological Environment Safety," Journal of Anhui Agricultural Sciences, 2010.

[48] S. Gu, Y. H. Tang, and X. Y. Cui, "Characterizing evapotranspiration over a meadow ecosystem on the Qinghai-Tibetan Plateau," Journal of Geophysical Research: Atmospheres, vol. 113, pp. 693-702, 2008.

[49] Q. I. Wen-Wen, B. P. Zhang, P. Yu, F. Zhao, and S. Zhang, "TRMM-Data-Based Spatial and Seasonal Patterns of Precipitation in the Qinghai-Tibet Plateau," Scientia Geographica Sinica, vol. 8, pp. 999-1005, 2013.

[50] J.Sun, G. W. Cheng, and W. P. Li, "Meta-analysis of relationships between environmental factors and aboveground biomass in the alpine grassland on the Tibetan Plateau," Biogeosciences, vol. 10, no. 3, pp. 1707-1715, 2013.

[51] X. Mei, B. Shen, and M. O. Shuhong, "Cause analysis of annual variation of evapotranspiration in guanzhong region," Water Resources \&amp; Power, 2012.

[52] J. Xie, X. Wei, C. Zhang, Y. U. Xiujing, and H. U. Yixin, "Spatiotemporal variation characteristics and related affecting factors of actual evapotranspiration in the second tributary of the Songhua and River basin, Northeast China," CJE, 2013.

[53] S. Wen, T. Jiang, X. Li, T. Wang, Y. Wang, and T. Fischer, "Changes of actual evapotranspiration over the songhua river basin from 1961 to 2010," Progressus Inquisitiones De Mutatione Climatis, vol. 2, pp. 79-86, 1961.

[54] Q. I. Wen-Wen, B. P. Zhang, Y. Pang, F. Zhao, and S. Zhang, "TRMM-data-based spatial and seasonal patterns of precipitation in the qinghai-tibet plateau," Scientia Geographica Sinica, vol. 8, pp. 999-1005, 2013.

[55] X. Zhao, W. Wan, and W. Wang, "Impact of climate change on potential productivity and phenological phase of forage in the Qinghai-Tibet Plateau in the past 50 years," Chinese Journal of Eco-Agriculture, vol. 4, pp. 532-543, 2016.

[56] Q. You, J. Min, W. Zhang, N. Pepin, and S. Kang, "Comparison of multiple datasets with gridded precipitation observations over the Tibetan Plateau," Climate Dynamics, vol. 45, no. 3-4, pp. 791-806, 2015.

[57] H. U. Haoran and L. Liang, "Temporal and spatial variations of rainfall at the east of qinghai- tibet plateau in last 50 years," Plateau \&amp; Mountain Meteorology Research, 2013.

[58] K. Tong, F. Su, D. Yang, L. Zhang, and Z. Hao, "Tibetan Plateau precipitation as depicted by gauge observations, reanalyses and satellite retrievals," International Journal of Climatology, vol. 34, no. 2, pp. 265-285, 2014.

[59] X. Li, M. Gemmer, J. Zhai, X. Liu, B. Su, and Y. Wang, "Spatiotemporal variation of actual evapotranspiration in the Haihe River Basin of the past 50 years," Quaternary International, vol. 304, pp. 133-141, 2013.

[60] Q. Z. Gao, Y. F. Wan, Y. Li, X. B. Qin, W. Jiangcun, and H. M. $\mathrm{Xu}$, "Spatial and temporal pattern of alpine grassland condition and its response to human activities in Northern Tibet, China," Rangeland Journal, vol. 32, no. 2, pp. 165-173, 2010.

[61] R. G. Allen, L. S. Pereira, D. Raes, and M. Smith, "Crop evapotranspiration. Guidelines for computing crop water requirements," Fao Irrigation \&amp; Drainage Paper, 1998.

[62] Y. H. Yin, S. H. Wu, and E. F. Dai, "Determining factors in potential evapotranspiration changes over China in the period
1971-2008," Chinese Science Bulletin, vol. 55, no. 29, pp. 3329$3337,2010$.

[63] Q. Zhang, C. Y. Xu, and X. Chen, "Reference evapotranspiration changes in China: natural processes or human influences?" Theoretical Applied Climatology, vol. 3, pp. 479-488, 2011.

[64] E.-M. Giannakopoulou and R. Toumi, "Impacts of the Nile Delta land-use on the local climate," Atmospheric Science Letters, vol. 13, no. 3, pp. 208-215, 2012.

[65] D. B. Anderson, "Relative humidity or vapor pressure deficit," Ecology, vol. 17, no. 2, pp. 277-282, 1936.

[66] S. Liu, S. Li, G. Yu et al., "Surface energy exchanges above two grassland ecosystems on the Qinghai-Tibetan Plateau," Biogeosciences Discussions, vol. 6, no. 5, pp. 9161-9192, 2009.

[67] Y. Zhang, C. Liu, Y. Tang, and Y. Yang, "Trends in pan evaporation and reference and actual evapotranspiration across the Tibetan Plateau," Journal of Geophysical Research D: Atmospheres, vol. 112, no. 12, Article ID D12110, 2007.

[68] Q. Mu, M. Zhao, F. A. Heinsch, M. Liu, H. Tian, and S. W. Running, "Evaluating water stress controls on primary production in biogeochemical and remote sensing based models," Journal of Geophysical Research: Biogeosciences, vol. 112, no. 1, Article ID G01012, 2007.

[69] H. Xie and X. Zhu, "Reference evapotranspiration trends and their sensitivity to climatic change on the Tibetan Plateau (1970-2009)," Hydrological Processes, vol. 27, no. 25, pp. 36853693, 2013.

[70] L. Yongchao, "Review on Impact of Climate Change on Water Resources System in the Upper Reaches of Yellow River," Advances in Climate Change Research, vol. 2, pp. 310-313, 2005.

[71] X. Li, S. Liang, W. Yuan et al., "Estimation of evapotranspiration over the terrestrial ecosystems in China," Ecohydrology, vol. 7, no. 1, pp. 139-149, 2014.

[72] L. A. Wever, L. B. Flanagan, and P. J. Carlson, "Seasonal and interannual variation in evapotranspiration, energy balance and surface conductance in a northern temperate grassland," Agricultural and Forest Meteorology, vol. 112, no. 1, pp. 31-49, 2002.

[73] S.-G. Li, C.-T. Lai, G. Lee et al., "Evapotranspiration from a wet temperate grassland and its sensitivity to micro-environmental variables," Hydrological Processes, vol. 19, no. 2, pp. 517-532, 2005.

[74] A. Hammerle, A. Haslwanter, U. Tappeiner, A. Cernusca, and G. Wohlfahrt, "Leaf area controls on energy partitioning of a temperate mountain grassland," Biogeosciences, vol. 5, no. 2, pp. 421-431, 2008.

[75] X. C. Zhang, S. Gu, and X. Q. Zhao, "Radiation partitioning and its relation to environmental factors above a meadow ecosystem on the Qinghai-Tibetan Plateau," Journal of Geophysical Research: Atmospheres, vol. 115, no. 10, Article ID D10106, 2010.

[76] Y. H. Yang, J. Y. Fang, P. A. Fay, J. E. Bell, and C. J. Ji, "Rain use efficiency across a precipitation gradient on the Tibetan Plateau," Geophysical Research Letters, vol. 37, no. 15, 2010.

[77] L. Zhang, W. R. Dawes, and G. R. Walker, "Response of mean annual evapotranspiration to vegetation changes at catchment scale," Water Resources Research, vol. 37, no. 3, pp. 701-708, 2001.

[78] T. A. Paço, T. S. David, M. O. Henriques et al., "Evapotranspiration from a Mediterranean evergreen oak savannah: The role of trees and pasture," Journal of Hydrology, vol. 369, no. 1-2, pp. 98-106, 2009. 

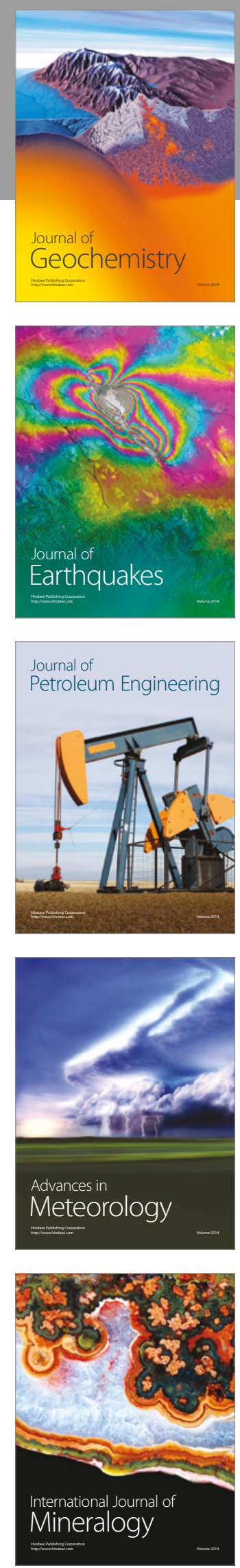
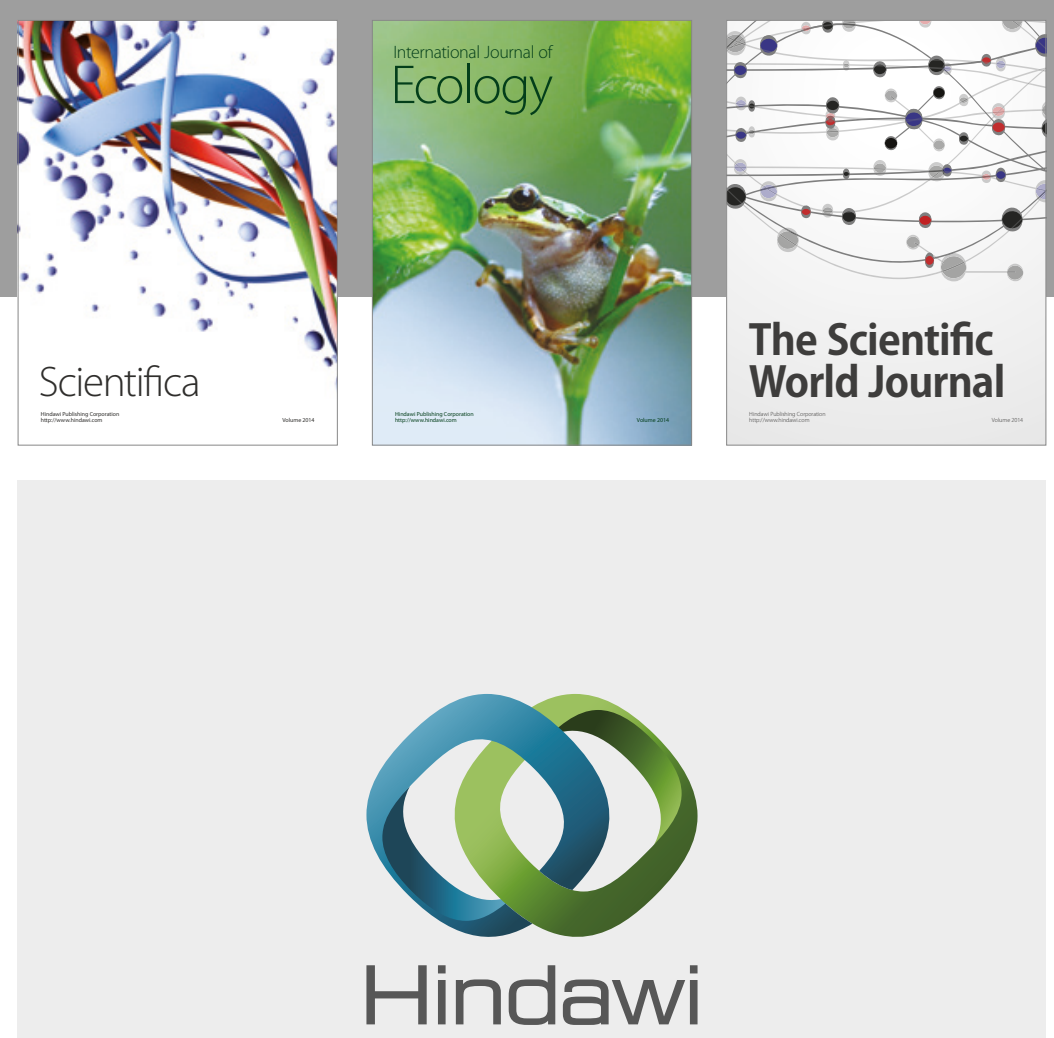

Submit your manuscripts at

https://www.hindawi.com
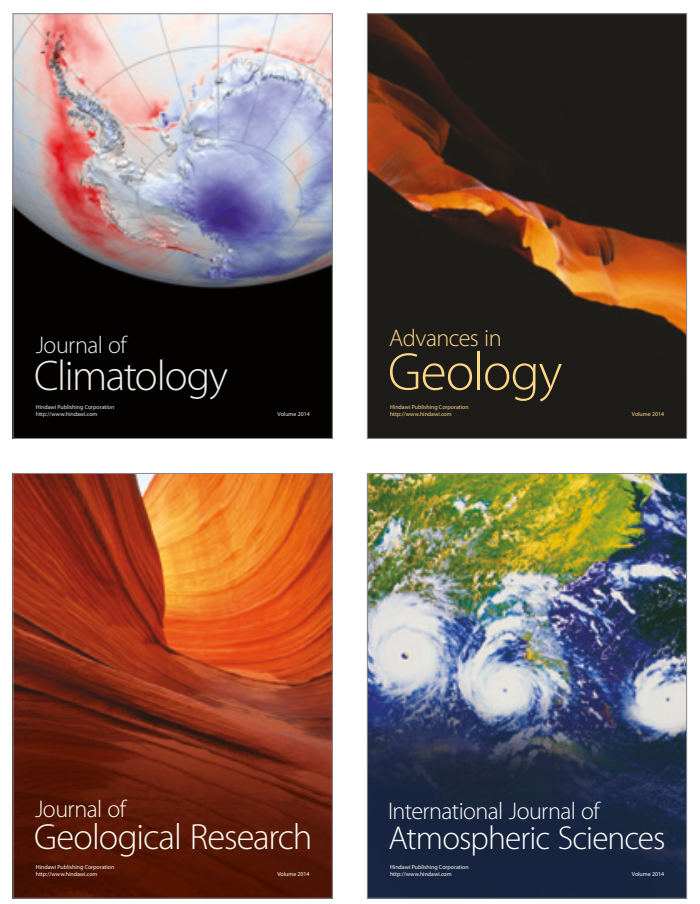

The Scientific

World Journal
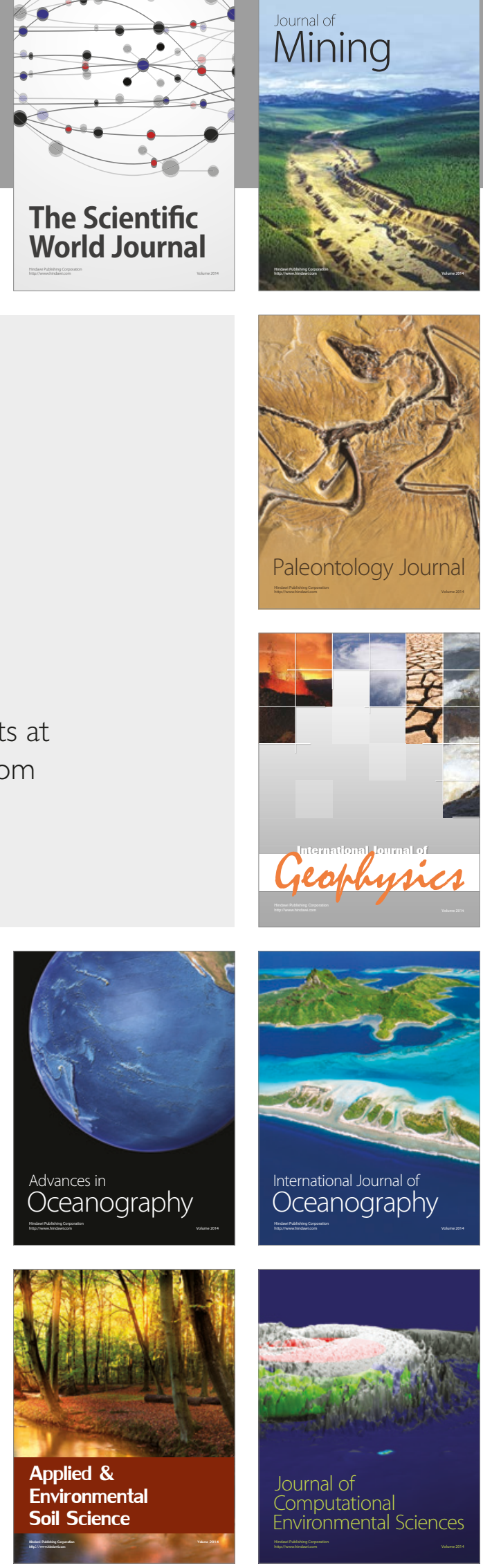